\title{
SYNTHESIS OF MAGNETICALLY RECYCLABLE SPINEL FERRITE (MFE2O4, M= ZN, CO, MN) NANOCRYSTALS ENGINEERED BY SOL GEL-HYDROTHERMAL TECHNOLOGY: HIGH CATALYTIC PERFORMANCES FOR NITROARENES REDUCTION
}

\section{ISLAM IBRAHIM, ${ }^{\mathrm{A}}$ IBRAHEEM O. ALI, ${ }^{\mathrm{A}}$ TAREK M. SALAMA, ${ }^{\mathrm{A} *}$ A. A. BAHGAT, ${ }^{\mathrm{B}}$ MO- HAMED MOKHTAR MOHAMED ${ }^{\mathrm{C}}$}

a*Al-Azhar University, Faculty of Science, Chemistry Department, Nasr City (11884), Cairo, Egypt ${ }^{b}$ Al-Azhar University, Faculty of Science, Physics Department, Nasr City (11884), Cairo, Egypt ${ }^{c}$ Benha University, Faculty of Science, Chemistry Department, Benha, Egypt

\begin{abstract}
Highly stable and magnetically recoverable $\mathrm{MFe}_{2} \mathrm{O}_{4}(\mathrm{M}=\mathrm{Zn}$, Co, Mn) spinel ferrite nanoparticles; synthesized using sol gel-hydrothermal technology via utilizing polyvinyl alcohol surfactant, were proposed as heterogeneous catalysts for the reduction of nitroarenes. The morphological characteristics, structural exploration, surface, optical, and vibrational properties were performed using powder X-ray diffraction, high-resolution transmission electron microscopy, energy dispersive $X$-ray, $N_{2}$ sorptiometry, diffused $U V$-visible reflectance spectroscopy. The results showed that $\mathrm{MnFe}_{2} \mathrm{O}_{4}$ exhibited the best performance in the reduction of 4-nitrophenol (4-NP), 2,4,6 tri-nitrophenol (2,4,6-NP) and 4-nitroaniline (4-NA) and revealed 100\% conversion into the corresponding amino derivatives in $270 \mathrm{sec}$ with rate constant equal $0.01061 \mathrm{sec}^{-1}, 0.01134 \mathrm{sec}^{-1}$ and 0.01355 $\mathrm{sec}^{-1}$, respectively. The superiority of the catalytic reduction of $\mathrm{MnFe}_{2} \mathrm{O}_{4}$ was due to increasing the pore radius and pore volume $(6.75 \mathrm{~nm}, 0.227 \mathrm{cc} / \mathrm{g})$ values compared to other nanoferrites. The synthesized nanoferrites indicate independence of the activity on crystallite sizes due to the insignificant margin of change (from 6 to $10 \mathrm{~nm}$ ). Conversely, decreasing the activity of $\mathrm{ZnFe}_{2} \mathrm{O}_{4}$ was due to increasing the $\mathrm{Zn}^{2+}$ ions size that induces an increase in lattice parameter values and thus increases the long-range electron transfer between $\mathrm{Fe}^{2+}-\mathrm{Fe}^{3+}$ ions. The $\mathrm{MnFe}_{2} \mathrm{O}_{4}$ catalyst that presented the highest saturation magnetization (135 emu/g) indicated the highest reduction potential for 4-NA comparatively in the presence of $\mathrm{NaBH}_{4}$ and the reduction reaction followed pseudo first-order kinetics. Increasing the reduction performance of 4-NA compared to other nitroaromatics on $\mathrm{MnFe}_{2} \mathrm{O}_{4}$ was explained based on the formed intermediates, their reactivities, and hydrophobicites.

Keywords: Nanoferrites; PVA template; MnFe2O4; Characterization; Nitroarenes reduction
\end{abstract}

\section{INTRODUCTION}

The great release of hazardous pollutants into the environment is increasing with the industrialization progression. Hazardous pollutants containing organic nitro compounds are distinctively dangerous because of their toxic and carcinogenic character [1]. Pure pollutants usually decompose at high temperatures, however, solutions of nitro compounds may decompose at much lower temperatures exhibiting large amounts of heat. Amongst these, the aromatic nitro compounds specially nitrophenols are the major pollutants existing in industrial and agricultural waste waters because of their solubility and stability in water [2]. On the other hand, nitroaniline, which dissolves in hot water and ethanol, causes respiratory tract irritation, anoxia due to the formation of methemoglobin and bone marrow abnormalities with damage to blood forming tissues [3]. Because of their dangerous nature, nitrophenols and nitroaniline have been arranged as priority pollutants by the U.S Environmental Protection Agency [4]. Besides, Picric Acid that is used as a primary explosive is highly toxic and dangerous material. Therefore, the removal of such pollutants from industrial waste water is crucial for environmental health. Therefore, many researchers are appointed to develop environmental and clean techniques for the removal of such pollutants from industrial waste water. Many redox processes have been managed for the removal of nitroaromatics such as catalytic moist air oxidation [5], photocatalytic degradation $[6,7]$, electrochemical processes [8-10], hydrogenation reactions [11, 12], etc. An important way to remove nitroaromatics and to get the maximum benefit is to carry out their reduction to aminoaromatics. Aminoaromatics are the most important constituents in the synthesis of many industrial dyes, pharmaceuticals, corrosion inhibitor, photographic developers and some biologically active compounds 
$[13,14]$. Many methods are available for the reduction of nitroaromatics to the corresponding aminoaromatics namely electrolytic reduction [15], metal/base reduction [16], homogenous catalysis [17], heterogeneous catalytic hydrogenation [18], photo-reduction $[19,20]$ and use of reducing agents like hydrazine hydrates [21], etc. Nevertheless, these methods are associated with one or more limitations such as problematic in catalyst retrieval, problems concerning discarding metal oxide sludge, time-consuming, hazardous effects of some of the used reagents, carcinogenic and mutagenic effects of hydrazine etc. However, reduction using $\mathrm{NaBH}_{4}$ was shown to be activated in the presence of suitable catalysts via giving the corresponding hydride [22]. For instance, transition metals in aqueous media produce metal borides in presence of $\mathrm{NaBH}_{4}$ that reduces nitro aromatics via evolution of $\mathrm{H}_{2}$ gas and production of hydride ion [23]. For example, Mandalimath and Gopal [24] carried out nitrophenols reduction using $\mathrm{NaBH}_{4}$ in the presence of group- $\mathrm{A}\left(\mathrm{CuO}, \mathrm{Co}_{3} \mathrm{O}_{4}, \mathrm{Fe}_{2} \mathrm{O}_{3}, \mathrm{NiO}\right)$ and group- $\mathrm{B}\left(\mathrm{TiO}_{2}, \mathrm{~V}_{2} \mathrm{O}_{5}, \mathrm{Cr}_{2} \mathrm{O}_{3}, \mathrm{MnO}_{2}\right.$ and $\left.\mathrm{ZnO}\right)$ of first row transition metal oxides. The first oxides enhanced the electron transfer process necessary for reduction whereas oxides of group B were inactive. It has also been demonstrated that [25] the catalytic reduction of nitrophenols can be obtained on high precious metals such as gold and silver nanocatalysts. The Au and Ag nanocatalysts those synthesized via different procedures $[20,24-25]$ and showed various morphologies were used to reduce nitroaromatics photo-catalytically based on their surface Plasmon resonances phenomena. Du et al. [26] exploited the nanocomposite $\mathrm{Fe}_{3} \mathrm{O}_{4} / \mathrm{SiO}_{2}(\mathrm{Ag})$ of microspheres shape for the reduction of 4-nitrophenol in aqueous medium at room temperature as a magnetic separable catalyst. Ni catalysts were the primer ones on their surfaces nitroaromatics reduction were performed. Lately, Kalbasi et al. [27] examined Nanoparticles-polyvinyl amine/SAB-15 catalyst for fast reduction of aromatic nitro compounds. On the other hand, ferrites of the type $\mathrm{MFe}_{2} \mathrm{O}_{4}$ with the spinel structure and magnetic properties were also utilized as catalysts for the reduction of nitrophenol. Feng et al. [28] examined the effectiveness of $\mathrm{CuFe}_{2} \mathrm{O}_{4}$ magnetic nanoparticles for the nitrophenol reduction that has been achieved in presence of 200 equivalent excess of $\mathrm{NaBH}_{4}$ at the conversion of $95 \%$ achieved in $40 \mathrm{~s}$. However, this later catalyst suffers from week stability and hard regeneration. So far very few reports are available where ferrites have been utilized as catalysts for the reduction of aromatic nitrocompounds in presence of $\mathrm{NaBH}_{4}$ as reducing agent. The use of ferrites as catalysts is very beneficial because of simple and facile synthetic procedure as well as their resistance to severe acidic and basic conditions. Their magnetic nature makes them magnetically separable from the reaction mixture in a convenient manner. Therefore, the present work deals with the investigation of comparative catalytic efficiency of pure ferrites $\mathrm{MFe}_{2} \mathrm{O}_{4}(\mathrm{M}=\mathrm{Mn}, \mathrm{Co}, \mathrm{Zn})$ synthesized by sol gel-hydrothermal method in the reduction reaction of nitrophenols (4-nitrophenol and 2,4,6-trinitrophenol) and 4-nitroaniline to the corresponding amino derivatives. The enhanced reduction efficiency of nanoferrites, effect of residual polyvinyl alcohol used while synthesis on surface, optical properties, and crystallites size has been evaluated in a firm way with the samples catalytic performances.

\section{Experimental}

\subsection{Materials}

Ferric chloride, zinc acetate, manganese formate, cobalt chloride, citric acid (99.57\%), sodium borohydride (97\%), polyvinyl alcohol $(\mathrm{PVA}$, Fluka, M.Wt $=1250,000)$ and sodium hydroxide were obtained from Fisher Scientific. 4-nitrophenol; 4-NP (99\%), 2,4,6-trinitrophenol; 2,4,6-NP (99\%) and 4-nitro-aniline; 4-NA (99\%), were purchased from S.D. Fine chemicals. All the chemicals were of analytical grade, commercially available and used without further purification.

\subsection{Catalyst fabrication}

Nano-ferrites $\mathrm{MFe}_{2} \mathrm{O}_{4}(\mathrm{M}=\mathrm{Mn}, \mathrm{Co}, \mathrm{Zn})$ were synthesized employing the sol gel- hydrothermal technique. The stoichiometric amounts of desired metal acetates and citric acid; used to acquire homogenous distribution of the metal ion (in the molar ratio 1:1), were separately dissolved in minimum amounts of distilled water. 
Synthesis of Magnetically Recyclable Spinel Ferrite (MFe2O4, M= Zn, Co,

On the other hand, iron chloride was dissolved in distilled water to give a molar ratio of $\mathrm{Fe} / \mathrm{M}$ $=2$. After complete dissolution, citric acid solution was poured onto the metal precursors followed by polyvinyl alcohol (PVA, 2 g/90 ml) addition whilst stirring. PVA plays many crucial roles in synthesizing nanoferrites including control of the nanoparticles growth, prevention of agglomeration and production of nanoparticles in uniform shapes [29]. Finally, $\mathrm{FeCl}_{3}$ solution was poured onto the later mixture followed by stirring for $0.5 \mathrm{~h}$. Addition of $\mathrm{NaOH}$ solution in step wise manner till reaching $\mathrm{pH}$ equal 12 was attained to the mixture that left under stirring for $1 \mathrm{~h}$. Indeed, condensation reactions are expected to occur between the metal ions and the citrates/ PVA to yield a complex or polymer network in a colloidal state known as sol facilitated by $\mathrm{NaOH}$ addition, which immediately form gel moieties. The resultant sol-gels were autoclaved for 48 $\mathrm{h}$ at $453 \mathrm{~K}$. Finally, the obtained mixtures were washed with distilled water and then annealed in an oven at $573 \mathrm{~K}$ for $6 \mathrm{~h}$.

\subsection{Physical measurements}

\subsubsection{X-ray diffraction}

$\mathrm{X}$-ray diffraction (XRD) was measured at room temperature by using a Philips diffractometer (type PW-3710). The patterns were run with $\mathrm{Ni}$-filtered copper radiation $(\lambda=1.5404 \AA)$ at 30 $\mathrm{kV}$ and $10 \mathrm{~mA}$ with a scanning speed of $2 \theta=$ $2.5^{\circ} / \mathrm{min}$. The mean particle size was calculated using the Debye-Scherrer Eq. (1), in which $\mathrm{K}$ is a constant equal $0.9, \lambda$ is the wavelength of the $\mathrm{Cu} \mathrm{K} \alpha$ radiation, $\beta$ is the half peak width of the diffraction peak in radiant[30].

$$
D=\frac{K \lambda}{\beta \cos \theta}
$$

\subsubsection{FTIR spectroscopy}

The Fourier transform infrared (FT-IR) spectra were recorded via a single beam Perkin Elmer Spectrometer (RXI FT-IR), with a resolution of $2 \mathrm{~cm}^{-1}$. The samples were grounded with $\mathrm{KBr}(1: 100)$ so as to form tablets, which mounted into the sample holder in the cavity of the spectrometer. The measurements were recorded at the room temperature in the region 4000-400 $\mathrm{cm}^{-1}$.

\subsection{3. $\mathrm{N}_{2}$ adsorption}

The surface properties namely BET surface area, total pore volume $\left(V_{\mathrm{p}}\right)$ and mean pore radius $(r)$ were determined from $\mathrm{N}_{2}$ adsorption isotherms measured at $77 \mathrm{~K}$ using conventional volumetric apparatus. The samples were outgassed at $473 \mathrm{~K}$ for $3 \mathrm{~h}$ under a reduced pressure of $10^{-5}$ Torr before starting the measurement. The total pore volume was taken from the desorption branch of the isotherm at $p / p^{0}=0.95$, assuming complete pore saturation.

\subsubsection{Ultraviolet-visible diffuse reflectance spectroscopy}

Diffuse Reflectance Ultraviolet-visible spectroscopy (UV-vis DRS) of the samples was carried out at room temperature using UV-vis JASCO spectrophotometer, $\mathrm{V}-570$, in the range of 200-1000 nm. The UV-vis spectra were processed with Microsoft Excel software, consisting of calculation of the Kubelka-Monk function, $F\left(R_{\infty}\right)$, which was extracted from the UV-vis DRS absorbance. The edge energy $\left(E_{\mathrm{g}}\right)$ for allowed transitions was determined by finding the intercept of the straight line in the low-energy rise of the plot of $\left[F\left(R_{\infty}\right) h v\right]^{2}$, for the direct allowed transition, vs $h v$, where $h v$ is the incident photon energy

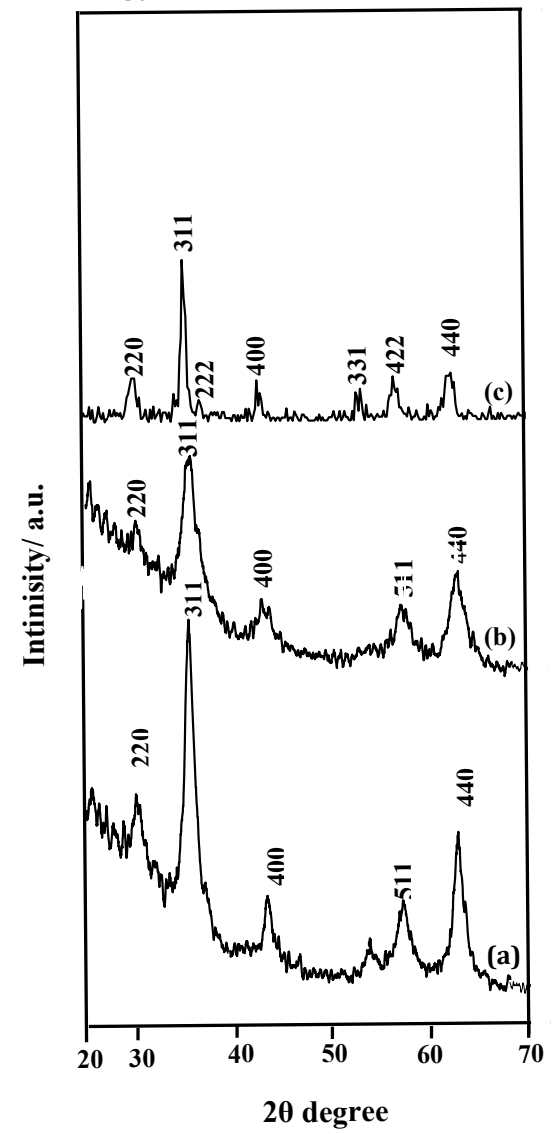

Fig.1: XRD patterns of (a) MnFe2O4, (b) CoFe2O4 and

(c) $\mathrm{ZnFe2O4samples} \mathrm{calcined} \mathrm{in} \mathrm{air} \mathrm{at} 573 \mathrm{~K}$. 


\subsubsection{Transmission Electron Microscope (TEM)}

TEM micrographs were measured using a FEI; model Tecnai G20, Super twin, double tilt 1010 , at an accelerating voltage of $200 \mathrm{KV}$. The powder samples were put on carbon foil with a microgrid. TEM images were observed with minimum electron irradiation to prevent damage to the sample structure. The elemental compositions of the composite material were investigated by energy-dispersive X-ray attached to the TEM equipment. The average particle diameter (d) was calculated by the following formula:

$$
d=\frac{\sum n_{i} d_{i}}{\sum n_{i}}
$$

where $n_{i}$ is the number of particle diameter $d_{i}$ in a certain range, and $\Sigma n_{i}$ is more than 100 particles on TEM images of the sample. Computerassisted counting of nanoparticle images and automated image analysis based software package including KONTRON KS 400 (Zeiss-Kontron) was used.

Table 1: State of spinel ferrite samples as characterized by X-ray diffraction, Surface Texturing and optical band gap (Eg).

\begin{tabular}{|c|c|c|c|c|c|c|c|c|c|c|c|c|}
\hline \multirow[b]{2}{*}{ Samples } & \multicolumn{3}{|c|}{ Data of XRD } & \multicolumn{4}{|c|}{ Surface Texturing } & \multicolumn{3}{|c|}{ Data of Magnetic } & \multirow{2}{*}{$\begin{array}{l}\text { Band } \\
\text { gap } \\
\text { (ev) }\end{array}$} & \multirow{2}{*}{$\begin{array}{c}\text { Average } \\
\text { Size by } \\
\text { TEM } \\
(\mathrm{nm})\end{array}$} \\
\hline & $\begin{array}{c}\text { Cryst. } \\
\text { size } \\
(\mathrm{nm})\end{array}$ & $\begin{array}{l}\text { Lattice } \\
\text { paramt. } \\
(\AA)\end{array}$ & $\begin{array}{c}\text { Cell Vol. } \\
(\AA)^{3}\end{array}$ & $\begin{array}{c}S_{\mathrm{BET}} \\
\left(\mathrm{m}^{2} / \mathrm{g}\right)\end{array}$ & $\begin{array}{c}S^{\text {ext }} \\
\left(\mathrm{m}^{2} / \mathrm{g}\right)\end{array}$ & $\begin{array}{c}\mathbf{r}^{-} \\
(\AA)\end{array}$ & $\begin{array}{r}\mathbf{V} \mathbf{p}^{\text {total }} \\
\left(\mathrm{cm}^{3} / \mathbf{g}\right)\end{array}$ & $\begin{array}{c}\text { Hc } \\
(\mathbf{O e})\end{array}$ & $\begin{array}{c}\mathrm{Mr} \\
(\mathrm{emu} / \mathrm{g})\end{array}$ & $\begin{array}{c}\text { Ms } \\
\text { (emu/g) }\end{array}$ & & \\
\hline $\mathrm{MnFe}_{2} \mathrm{O}_{4}$ & 2.34 & 8.365 & 585.433 & 67.1 & 67.1 & 67.5 & 0.227 & 48.0 & 42. & 135 & 1.25 & 10.6 \\
\hline $\mathrm{CoFe}_{2} \mathrm{O}_{4}$ & 5.88 & 8.379 & 588.352 & 114 & 114 & 34.1 & 0.194 & 49.9 & 40.1 & 37 & 0.9 & 8.72 \\
\hline $\mathrm{ZnFe}_{2} \mathrm{O}_{4}$ & 2.58 & 8.411 & 595.081 & 91.6 & 91.6 & 35.1 & 0.160 & 48.6 & - & - & 1.3 & 6.27 \\
\hline
\end{tabular}

Table 2: Decomposition temperature, order and activation parameters of spinel ferrite prepared by hydrothermal methods (Horowitz and Gershon Metzger)

\begin{tabular}{|l|c|c|c|c|c|c|c|c|}
\hline Samples & Step & $\mathrm{T} / \mathrm{K}$ & $\mathrm{A} / \mathrm{S}^{-1}$ & $\mathrm{E} / \mathrm{KJ} \mathrm{mol}^{-1}$ & $\mathrm{R}^{2}$ & $\begin{array}{l}\Delta \mathrm{H}^{*} / \mathrm{KJ}^{-1} \\
\mathrm{~mol}^{-1}\end{array}$ & $\begin{array}{l}\Delta \mathrm{S}^{*} / \mathrm{KJ} \\
\mathrm{mol}^{-1} \mathrm{~K}^{-1}\end{array}$ & $\begin{array}{l}\Delta \mathrm{G}^{*} / \mathrm{KJ} \\
\mathrm{mol}^{-1}\end{array}$ \\
\hline \multirow{3}{*}{$\mathrm{MnFe}_{2} \mathrm{O}_{4}$} & First & 328 & $2.05 \times 10^{3}$ & 30.082 & 0.986 & 27.3523 & -0.163 & 80.927 \\
\cline { 2 - 9 } & Second & 642 & $1.16 \times 10^{14}$ & 188.579 & 0.947 & 183.236 & 0.037 .114 & 159.379 \\
\cline { 2 - 9 } $\mathrm{CoFe}_{2} \mathrm{O}_{4}$ & Third & 769 & $6.38 \times 10^{-9}$ & 126.747 & 0.998 & 120.350 & -0.428 & 450.317 \\
\cline { 2 - 9 } & Second & 763 & $9.96 \times 10^{7}$ & 139.431 & 0.998 & 133.083 & -0.080 & 194.533 \\
\cline { 2 - 9 } & Third & 1231 & $1.30 \times 10^{13-}$ & 313.216 & 0.916 & 302.974 & -0.522 & 946.819 \\
\hline \multirow{3}{*}{$\mathrm{ZnFe}_{2} \mathrm{O}_{4}$} & First & 332 & $1.58 \times 10^{3}$ & 29.839 & 0.988 & 27.075 & -0.165 & 82.081 \\
\cline { 2 - 9 } & Second & 551 & $2.57 \times 10^{4}$ & 63.466 & 0.961 & 58.880 & -0.146 & 139.683 \\
\cline { 2 - 9 } & Third & 1222 & $2.97 \times 10^{11-}$ & 253.546 & 0.993 & 243.385 & -0.477 & 826.816 .9 \\
\hline
\end{tabular}




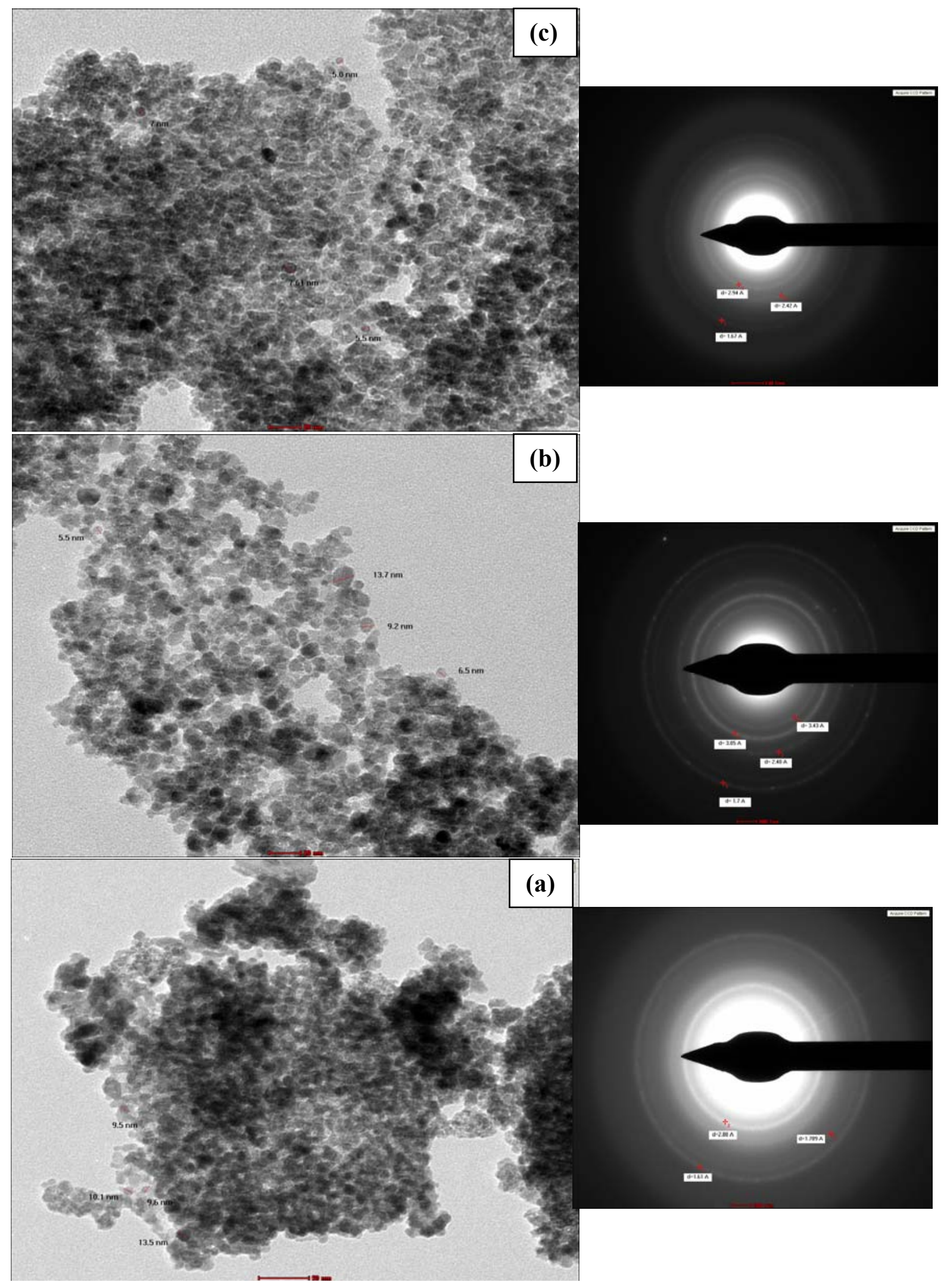

Fig. 2: TEM images and SAED of (a) $\mathrm{MnFe2O4}$, (b) $\mathrm{CoFe2O} 4$ and (c) $\mathrm{ZnFe2O} 4$ samples

calcined in air at $573 \mathrm{~K}$. 
Islam Ibrahim, et al.

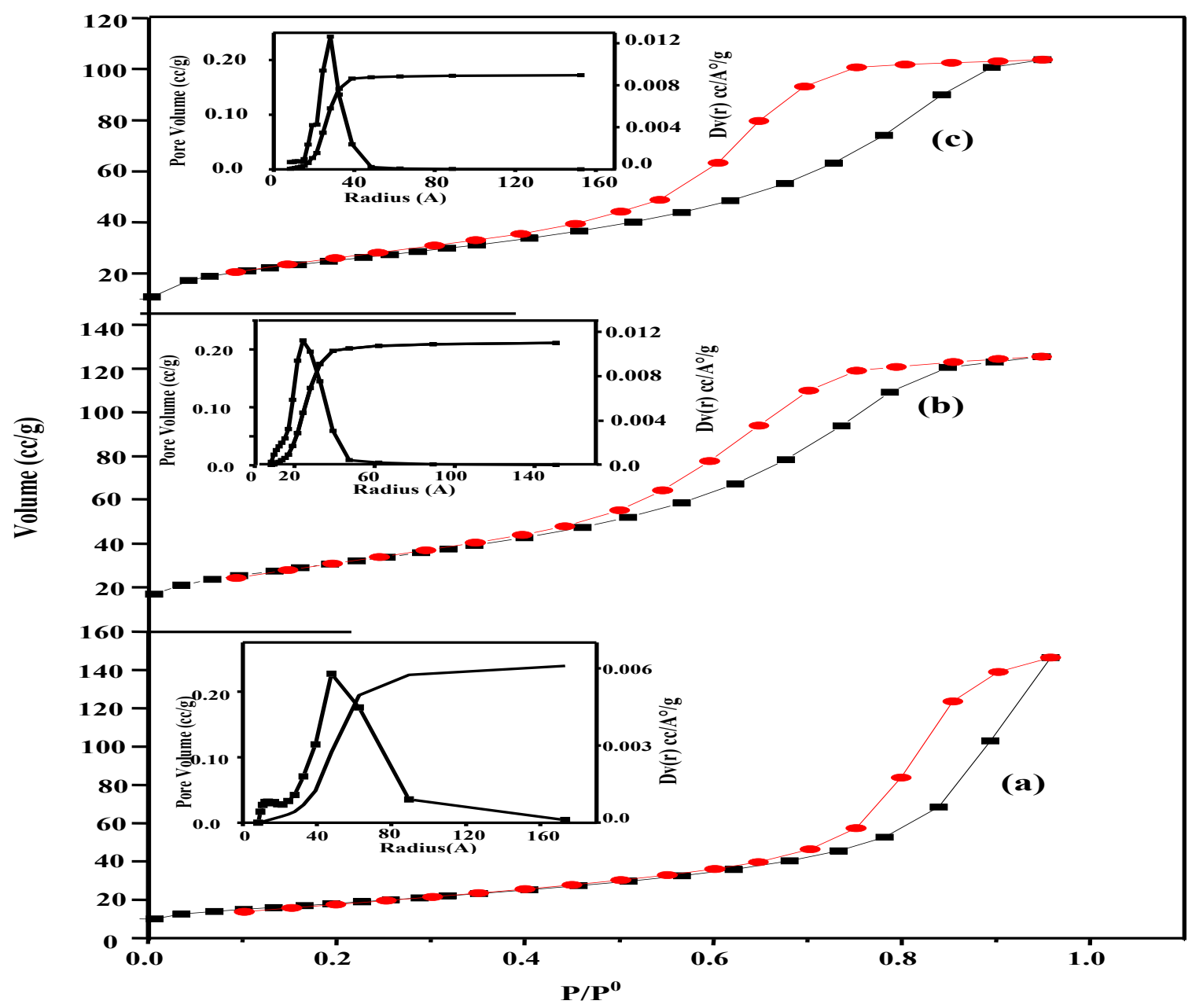

Fig. 3:N2 adsorption-desorption isotherms and corresponding pore size distribution curves of (a) $\mathrm{MnFe2O4}$,

(b) $\mathrm{CoFe} 2 \mathrm{O} 4$ and (c) $\mathrm{ZnFe} 2 \mathrm{O} 4$ samples calcined in air at $573 \mathrm{~K}$.

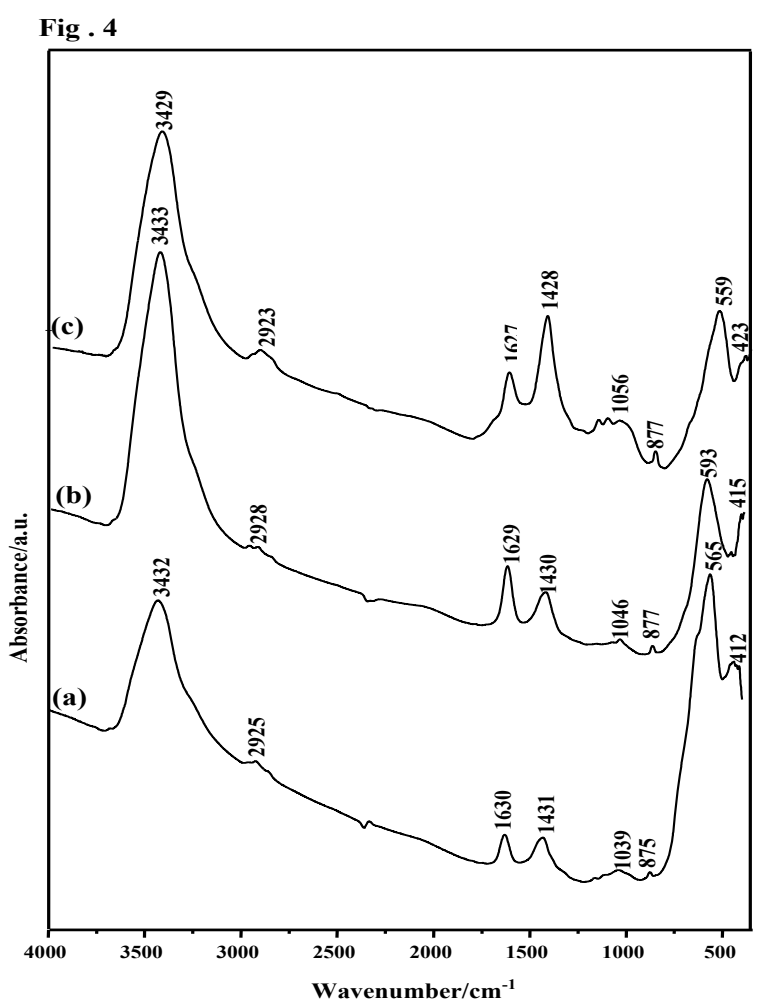

Fig. 4: FT-IR absorbance spectra of (a) $\mathrm{MnFe2O4,} \mathrm{(b)}$ $\mathrm{CoFe} 2 \mathrm{O} 4$ and (c) $\mathrm{ZnFe} 2 \mathrm{O} 4$ samples calcined in air at $573 \mathrm{~K}$. 
Synthesis of Magnetically Recyclable Spinel Ferrite (MFe2O4, M= Zn, Co,

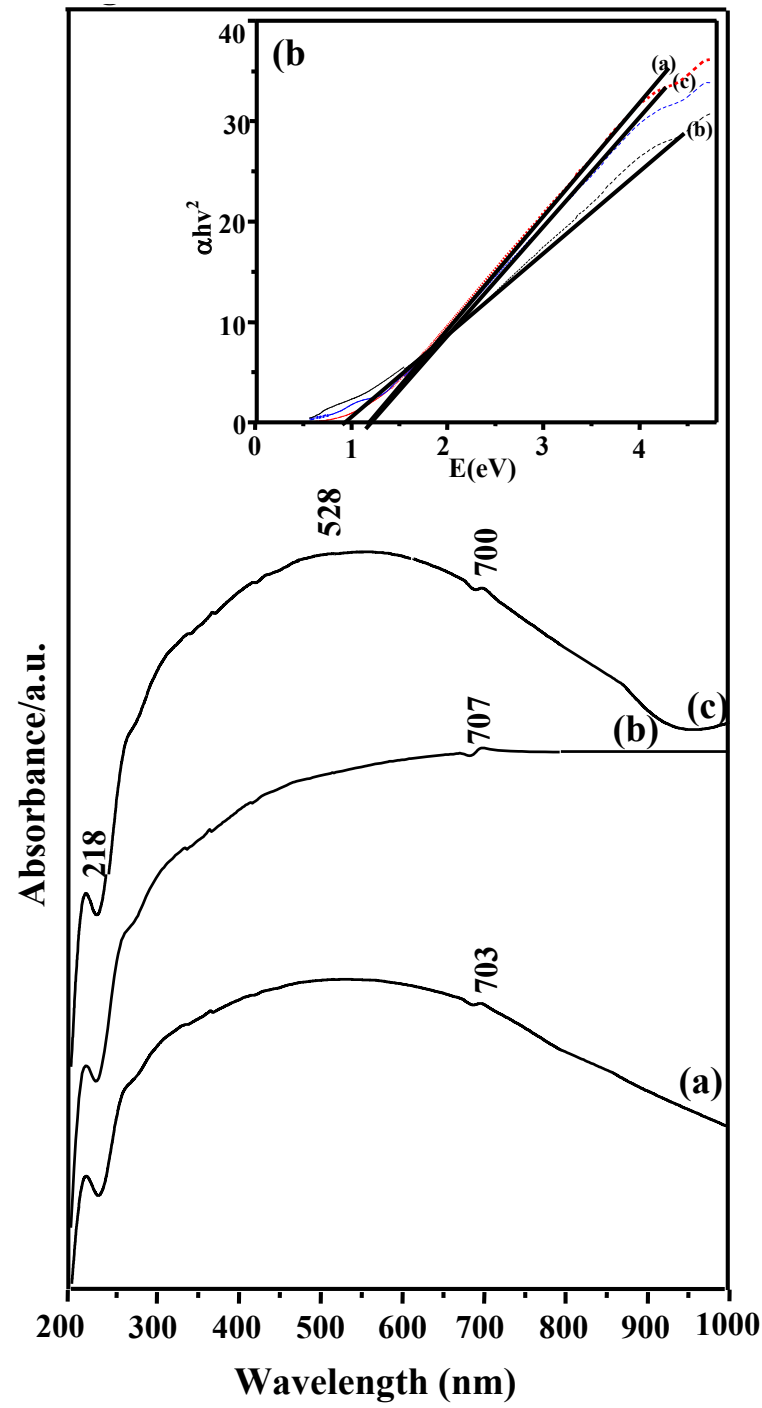

Fig. 5: Diffuse reflectance versus wavelength for (a)

$\mathrm{MnFe2O4,} \mathrm{(b)} \mathrm{CoFe} 2 \mathrm{O} 4$ and (c) $\mathrm{ZnFe} 2 \mathrm{O} 4$ samples calcined in air at $573 \mathrm{~K}$. The inset shows the graphical representation of $(F(R)$. h2( $\square$ vs. h $\square$.

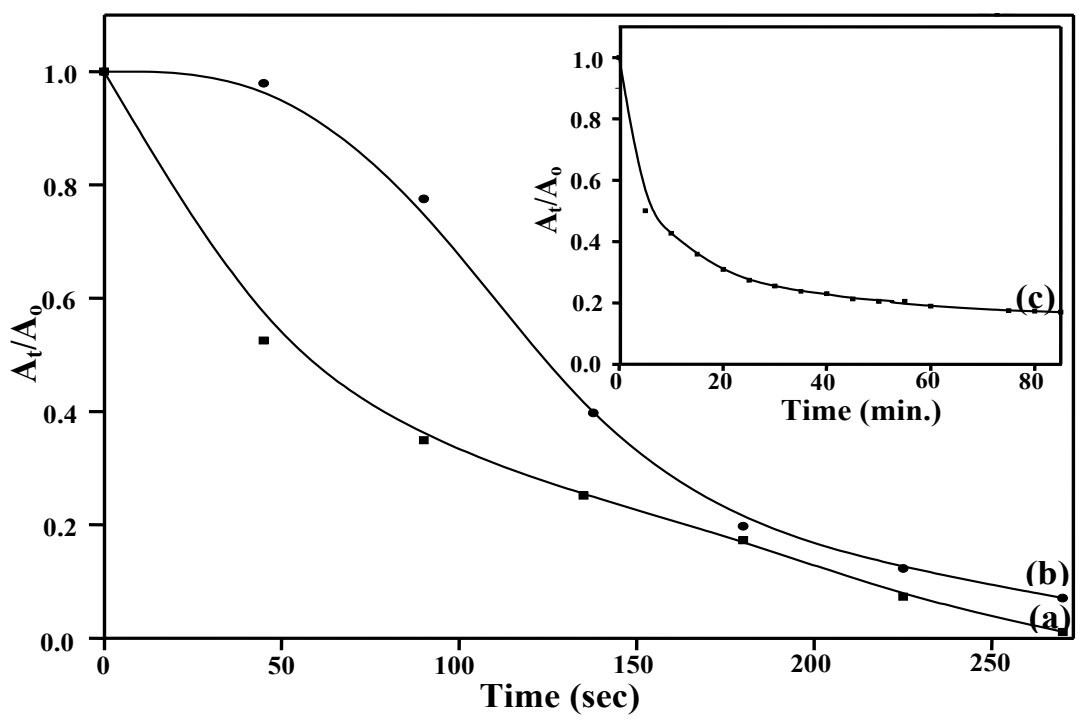

Fig. 7: The change in the concentration of 4-NP with time in the reduction of 4-NP by $\mathrm{MnFe2O4}$ in the presence of aqueous NaBH4. Reaction conditions: $100 \mathrm{~mL} \quad 4-\mathrm{NP}$ of conc. $0.1 \mathrm{mmol} \mathrm{L-1,}$ NaBH4 conc. Of $0.5 \mathrm{M}$, 0.1 g catalyst, $T=298 \mathrm{~K}$. 
Islam Ibrahim, et al.

Fig. 8: Plots of $\ln (\mathrm{At} / \mathrm{A} 0)$ vs. time for the reduction of 4-NP in the presence of (a) $\mathrm{MnFe2O} 4$ and (b) $\mathrm{CoFe} 2 \mathrm{O} 4$ and in set (c) $\mathrm{ZnFe} 2 \mathrm{O}^{2}$ samples calcined in air at 573 $K$. Reaction conditions: $100 \mathrm{~mL}$ 4-NP of conc. 0.1 mmol L-1, NaBH4 conc. Of $0.5 \mathrm{M}, 0.1 \mathrm{~g}$ catalyst, $T=298 \mathrm{~K}$.
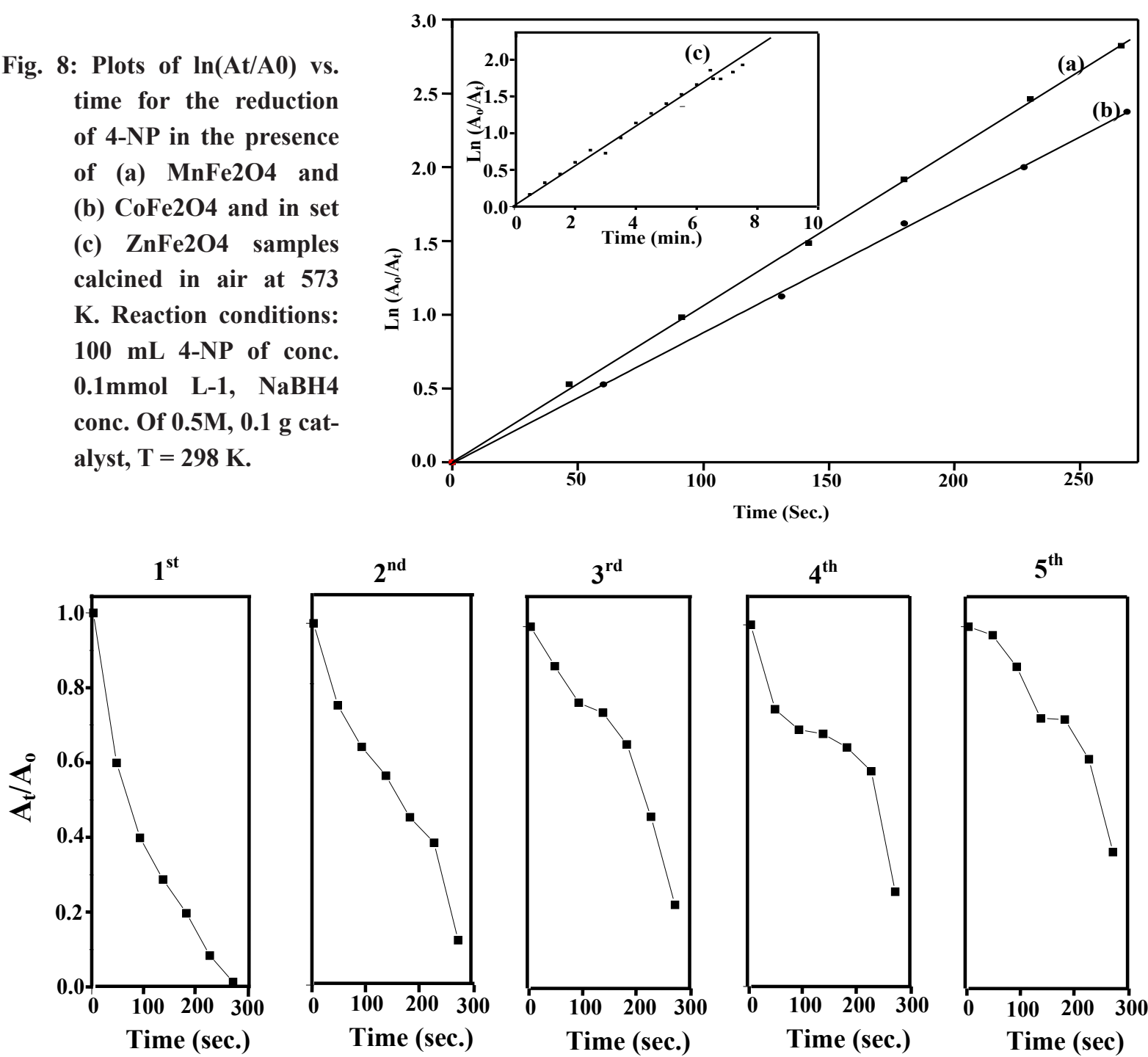

Fig. 9: Repeated cycles up to 5 times illustrating the reduction of 4-NP over MnFe2O4 . Reaction conditions: $100 \mathrm{~mL}$ 4-NP of conc. $0.1 \mathrm{mmol} \mathrm{L-1,} \mathrm{NaBH} 4$ conc. of $0.5 \mathrm{M}, 0.1 \mathrm{~g}$ catalyst, $\mathrm{T}=298 \mathrm{~K}$.

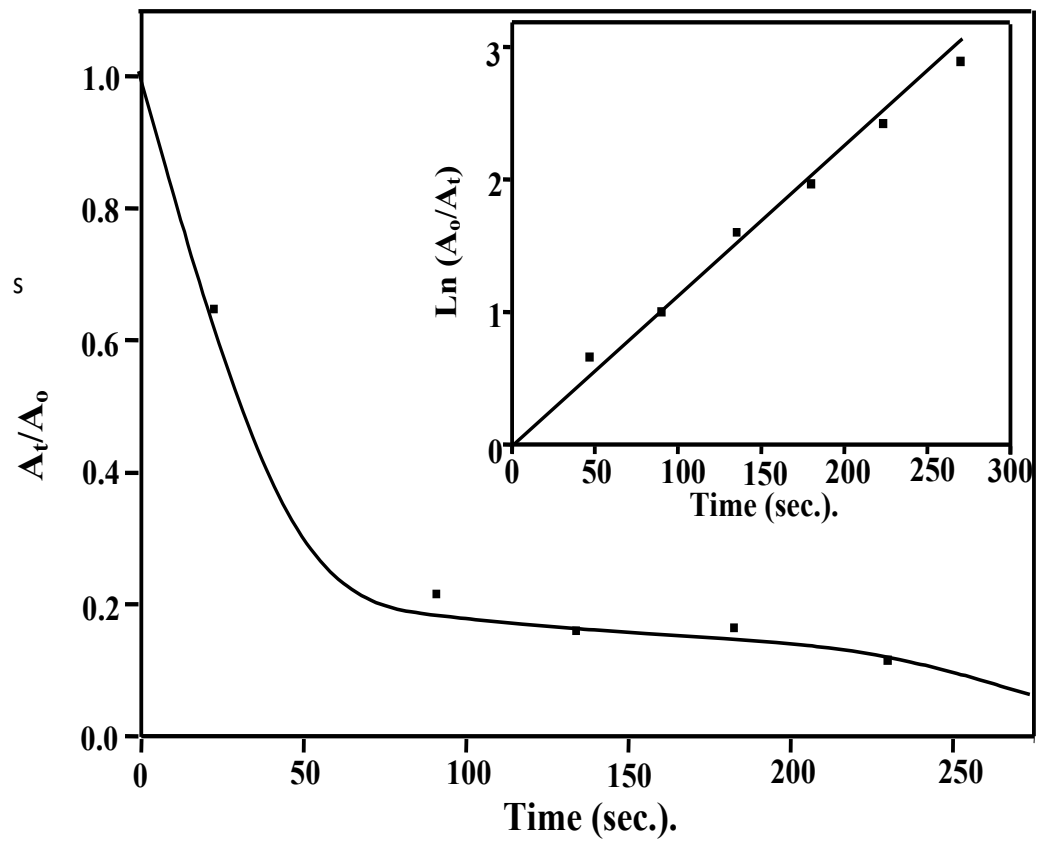

Fig. 10: The change in the concentration of picric acid reduction with time in presence of $\mathrm{MnFe2O} 4$ catalyst, and in-set is the Ln A0/At vs. time of the same graph. Reaction conditions: $100 \mathrm{~mL} \mathrm{4-NP}$ of conc. $0.1 \mathrm{mmol} \mathrm{L-1}$, $\mathrm{NaBH} 4$ conc. Of $0.5 \mathrm{M}$, $0.1 \mathrm{~g}$ catalyst, $\mathrm{T}=298 \mathrm{~K}$. 


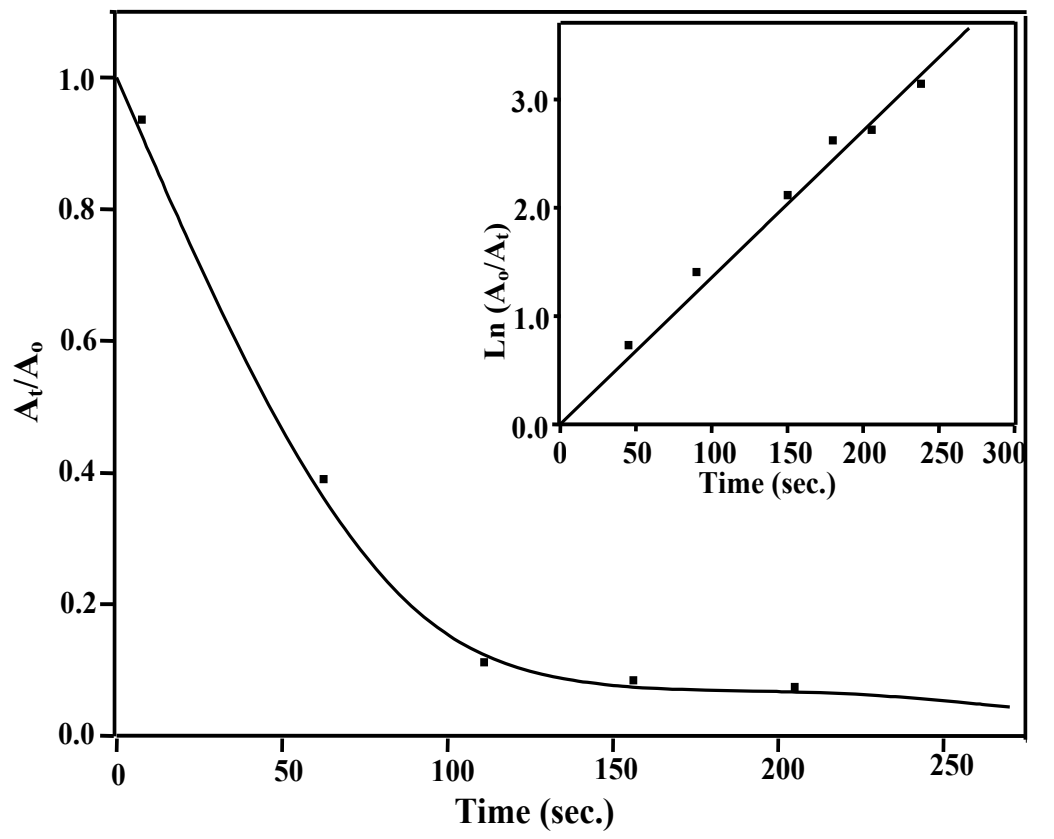

Fig. 11: The change in the concentration of p-nitroaniline reduction with time in presence of $\mathrm{MnFe2O} 4$ catalyst in the presence of aqueous $\mathrm{NaBH} 4$ with reduction, and the in-set is $\mathrm{Ln} \mathrm{A0/At} \mathrm{vs} \mathrm{time} \mathrm{of}$ the same graph. Reaction conditions: $100 \mathrm{~mL} \mathrm{4-NP}$ of conc. $0.1 \mathrm{mmol} \mathrm{L-1,}$ $\mathrm{NaBH} 4$ conc. Of $0.5 \mathrm{M}, 0.1$ g catalyst, $T=298 \mathrm{~K}$.

\subsection{Catalytic reaction}

To investigate the catalytic reduction of 4-nitrophenols, 2,4,6-trinitrophenol and 4-nitroaniline, $100 \mathrm{ml}$ of $0.1 \mathrm{mmol}$ aqueous solution of the nitroaromatics were taken in a $100 \mathrm{ml}$ beaker and $12.5 \mathrm{ml}$ of $0.5 \mathrm{M}$ (5 equivalents) of $\mathrm{NaBH}_{4}$ was added. The solution was subjected to constant stirring. with the addition of $\mathrm{NaBH}_{4}$, the yellow color of the solution was darkened due to the formation of phenolate ions. A desired amount of $\mathrm{MFe}_{2} \mathrm{O}_{4}(\mathrm{M}=\mathrm{Mn}, \mathrm{Co}, \mathrm{Zn})$ nanoferrite catalysts was added; so as to reaching $1 \mathrm{~g} / 1$, while stirring was continued at room temperature. The dark yellow color of the solution progressively vanished, demonstrating the reduction of nitroaromatics. The reaction progress was checked via withdrawing samples from the reaction mixture at normal time intervals. The conversion of nitroaromatics to the corresponding aminoaromatics was checked by UV-Visible spectroscopy (a Perkin Elmer Lamda-900) by measuring the absorption maxima corresponding to reactant nitrocompounds as well as product aminocompounds. After the completion of reaction, i.e. after complete disappearance of the yellow color, the catalyst was separated with the help of an external magnet. The selective formation of aminoaromatics and their reaction kinetics were determined via capillary column gas chromatography (varian 3900) to confirm that the amino-products were the only ones at the end of the reaction.

\section{RESULTS AND DISCUSSION}

\section{The structure and morphology of nanoferrites}

The purity and crystallinity of as synthesized nanoferrites were examined by XRD and shown in Fig.1. All the strong sharp diffraction peaks in $\mathrm{CoFe}_{2} \mathrm{O}_{4}$ (JCPDS 22-1086), $\mathrm{MnFe}_{2} \mathrm{O}_{4}$ (JCPDS 73-1964) and $\mathrm{ZnFe}_{2} \mathrm{O}_{4}$ (JCPDS 221012) samples are well indexed respectively, to the corresponding cubic spinel structure and a face-centered cubic (fcc) phase with $\mathrm{Fd} 3 \mathrm{~m}$ space group. The obtained patterns indicate that the synthesized samples are highly crystalline and in single phase without impurities. In conformity, The lattice constant $a$ calculated from the patterns of $\mathrm{CoFe}_{2} \mathrm{O}_{4}, \mathrm{MnFe}_{2} \mathrm{O}_{4}$ and $\mathrm{ZnFe}_{2} \mathrm{O}_{4}$ samples was $8.379,8.365$ and $8.411 \AA$ respectively (Table 1), very close to the reported data ( $a=8.360-8.511 \AA$ ) [30]. Increasing the lattice parameter for $\mathrm{Zn}$ ferrite is due to increasing the ionic radius of $\mathrm{Zn}^{2+}(0.82 \AA)$ relative to other metal ions leading to an expansion. Accordingly, this indeed indicates that the sol gel-hydrothermal is a perfect method for the spinel synthesis without extra phases. The morphologies of Co$\mathrm{Fe}_{2} \mathrm{O}_{4}, \mathrm{MnFe}_{2} \mathrm{O}_{4}$ and $\mathrm{ZnFe}_{2} \mathrm{O}_{4}$ were characterized by TEM (Fig. 2). The obtained TEM image of $\mathrm{ZnFe}_{2} \mathrm{O}_{4}$ revealed a nanocircular structure with an average size of $6.27 \mathrm{~nm}$. The illustrated selected area electron diffraction (SAED) pattern of $\mathrm{ZnFe}_{2} \mathrm{O}_{4}$ nanoparticles is indexed perfectly to 
Islam Ibrahim, et al.

the face centred cubic structure via the existed facets at $2.94,2.42$ and $1.67 \AA$, in agreement with XRD results. Similarly, the TEM images of $\mathrm{CoFe}_{2} \mathrm{O}_{4}$ and $\mathrm{MnFe}_{2} \mathrm{O}_{4}$ those demonstrated high crystalline nanoparticles of spherical shape indicate, respectively average diameters equal 8.72 $\mathrm{nm}$ and $10.6 \mathrm{~nm}$. The obtained rings in SAED patterns of later samples are perfectly indexed to highly crystalline pure cubic phase via notifying the facets at $3.43,3.05,2.40$, and $1.7 \AA$ for $\mathrm{CoFe}_{2} \mathrm{O}_{4}$ and 2.80, 1.78 and $1.61 \AA$ for $\mathrm{MnFe}_{2} \mathrm{O}_{4}$.

\subsection{Surface properties}

The $\mathrm{N}_{2}$ adsorption-desorption isotherms for the nanoferrites are shown in Fig. 3 together with the corresponding pore size distribution curves. The $\mathrm{N}_{2}$ adsorption-desorption isotherms for all of the nanoferrites exhibit type IV isotherm, which are typical of mesoporous materials, with a type $\mathrm{H}_{2}$ hysteresis loop associated to capillary condensation in the mesopores. $\mathrm{ZnFe}_{2} \mathrm{O}_{4}$ shows broader hysteresis loop than $\mathrm{CoFe}_{2} \mathrm{O}_{4}$ covering the range from $\mathrm{p} / \mathrm{p}^{0}=0.12$ to 0.95 where the later covers the range from $\mathrm{p} / \mathrm{p}^{\mathrm{o}}=0.22$ to 0.95 . This points that $\mathrm{ZnFe}_{2} \mathrm{O}_{4}$ contains higher percentages of micropore type of pores. On the other hand, $\mathrm{MnFe}_{2} \mathrm{O}_{4}$ occurs in the pressure range from 0.55 to 0.95 emphasizing the mesoporosity type of pores. The pore size distribution curves displayed unimodal type of pores covering the range from 15 to $50 \AA$ in $\mathrm{ZnFe}_{2} \mathrm{O}_{4}$ with a maximum distribution at $30 \AA$ where that of $\mathrm{CoFe}_{2} \mathrm{O}_{4}$ indicates a maximum at $28 \AA$ displayed in the range from 9 to $48 \AA$. On the other hand, Mn$\mathrm{Fe}_{2} \mathrm{O}_{4}$ indicates bimodal distribution at 10 and $60 \AA$ highlighting the increase of the mesoporosity of this sample comparatively. The BET surface area, pore volume and pore diameter of synthesized nanoferrites are given in Table 1 . The surface area of nanoferrite catalysts follows the order: $\mathrm{CoFe}_{2} \mathrm{O}_{4}>\mathrm{ZnFe}_{2} \mathrm{O}_{4}>\mathrm{MnFe}_{2} \mathrm{O}_{4}$, whereas $\mathrm{MnFe}_{2} \mathrm{O}_{4}$ indicated the highest pore volume and pore radius values. The reduction in the surface area of $\mathrm{ZnFe}_{2} \mathrm{O}_{4}\left(91.6 \mathrm{~m}^{2} / \mathrm{g}\right)$ compared to Co$\mathrm{Fe}_{2} \mathrm{O}_{4}\left(114.21 \mathrm{~m}^{2} / \mathrm{g}\right)$ confirms the presence of residual organics blocking some mesopores in $\mathrm{Zn}$ $\mathrm{Fe}_{2} \mathrm{O}_{4}$; as will be confirmed from IR results, and probably transferred some of it into micropores; as evident from the isotherm tail of this sample.
Whereas, the reduction confirmed in $\mathrm{MnFe}_{2} \mathrm{O}_{4}$ $\left(67.1 \mathrm{~m}^{2} / \mathrm{g}\right)$ is probably due to increasing both pore volume and radius comparatively. Moreover, the marked enhancement in surface area and pore volume of our synthesized nanoferrites compared to those fabricated by others such as pure $\mathrm{ZnFe}_{2} \mathrm{O}_{4}$-MM (11.51 $\left.\mathrm{m}^{2} \mathrm{~g}^{-1}\right), \mathrm{ZnFe}_{2} \mathrm{O}_{4}$-NP $\left(3.30 \mathrm{~m}^{2} \mathrm{~g}^{-1}\right)$ and hybrid of $\mathrm{ZnFe}_{2} \mathrm{O}_{4}$ with graphene $\left(26.35 \mathrm{~m}^{2} \mathrm{~g}^{-1}\right)$ was observed [31]. This probably due to the templating route attained via using PVA in creating mesopores based on selfassembly of this nonionic surfactant with the ferrite precursors. The average pore diameter calculated by the Barrett-Joyner-Halenda (BJH) method for the entire nanoferrites indicates a value around 34-35 $\AA$ for $\mathrm{ZnFe}_{2} \mathrm{O}_{4}$ and $\mathrm{CoFe}_{2} \mathrm{O}_{4}$ and $67.5 \AA$ for $\mathrm{MnFe}_{2} \mathrm{O}_{4}$ which is clear evidence for the formation of mesoporous structure with uniform size. Indeed, the unique spherical particles with ordered cubic spinel structure and of mesoporous nature may provide more active sites for absorption of nitroarene molecules, resulting in an enhanced catalytic reduction activity especially for $\mathrm{MnFe}_{2} \mathrm{O}_{4}$.

\subsection{FTIR Study}

FTIR spectra are employed to verify the nanoferrites formation after calcining at $573 \mathrm{~K}$ in the wavenumber range of $400-4000 \mathrm{~cm}^{-1}$. All the spectra show (Fig. 4) two principle absorption bands in the range of $400-600 \mathrm{~cm}^{-1}$. These two vibrational bands correspond to $\mathrm{Fe}-\mathrm{O}$ and $\mathrm{M}$ ( $\mathrm{Zn}, \mathrm{Co}$ and $\mathrm{Mn}$ )-O assigned respectively, to intrinsic lattice vibrations of octahedral (412$423 \mathrm{~cm}^{-1}$ ) and tetrahedral coordination (565-593 $\mathrm{cm}^{-1}$ ) in the spinel structure [32]. Shifting the latter into longer wavenumbers than that of the former was due to shortening the bond length in tetrahedral structure than that in octahedral one. The stretching vibration of the Co-O $\left(593 \mathrm{~cm}^{-1}\right)$ group exhibited a significant shift towards high wavenumbers compared to other tetrahedral vibrations (559-565 $\left.\mathrm{cm}^{-1}\right)$, suggesting a strong hybridization between $\mathrm{Co}$ and $\mathrm{Fe}$ while forming $\mathrm{CoFe}_{2} \mathrm{O}_{4}$. This was in part due to decreasing the ionic radius of $\mathrm{Co}^{2+}$ as well as increasing its electronegativity (1.88) compared to rest metals. This also specifies that more $\mathrm{Co}^{2+}$ ions move to tetrahedral positions. On the other hand, increas- 
ing the ionic radius of $\mathrm{Zn}^{2+}$ ions makes the $\mathrm{Fe}^{3+}$ ions migrate to the octahedral sites, and consequently decreases the tetrahedral vibration frequency $\left(559 \mathrm{~cm}^{-1}\right)$, to be the lowest comparatively. Conversely, migration of the $\mathrm{Fe}^{3+}$ ions to the octahedral site increases the octahedral vibration frequency $\left(423 \mathrm{~cm}^{-1}\right)$. The bands with peaks in the range of $1039-1056 \mathrm{~cm}^{-1}$ and $875(877) \mathrm{cm}^{-1}$ were assigned, respectively to the $\mathrm{C}-\mathrm{O}$ stretching vibrations and to $\mathrm{C}-\mathrm{C}$ stretching vibrations. The bands in the range of 1428 to $1431 \mathrm{~cm}^{-1}$ are associated with $\mathrm{C}-\mathrm{H}$ bending vibration of methylene groups whereas those localized at $\sim 1630$ $\mathrm{cm}^{-1}$ and $\sim 3432 \mathrm{~cm}^{-1}$ were associated to the deformation of $\mathrm{H}_{2} \mathrm{O}$ vibration and $\mathrm{O}-\mathrm{H}$ stretching vibration, respectively [33]. This suggests that thermal treatment at $573 \mathrm{~K}$; as performed to our samples, did not remove all organics/PVA moieties however, residual carbonaceous compounds were exposed on all ferrite surfaces. It seems also from the spectra that $\mathrm{MnFe}_{2} \mathrm{O}_{4}$ has the lowest band intensities occurred in the 800$4000 \mathrm{~cm}^{-1}$ range revolving that it contains the lowest carbonaceous compounds as well as water of hydration probably due to decreasing its ionic radius .

\subsection{Optical study}

In order to elucidate the optical response and to determine the band gaps of the nanoferrite samples, UV-visible diffuse reflectance spectroscopy (UV-vis DRS) was carried out, and the results are depicted in Fig.5. The spectral reflectance was measured in the wavelength range of 200-1000 nm. Although the spectral shapes are generally same, there are prominent differences in the reflection edges. All the samples exhibit a band at $218 \mathrm{~nm}$ together with a broad one at $270 \mathrm{~nm}$. These bands are respectively assigned to $\pi-\pi \square$ and $n-\pi \square$ transitions emphasizing the presence of residual organics. An apparent enhancement of the absorption throughout the visible-light region is observed with for all samples till $1000 \mathrm{~nm}$. This probably correlated to the exhibited dispersion and to the strong interaction between $\mathrm{M}(\mathrm{Zn}, \mathrm{Co}, \mathrm{Mn})-\mathrm{O}$ and $\mathrm{Fe}-\mathrm{O}$; as evidenced previously using XRD and IR results. The absorption shoulders of the nanoferrite spectra in the visible regions $(500-750 \mathrm{~nm})$ may be attributed to the electron excitation from the $\mathrm{O}^{-2} \mathrm{p}$ level into the $\mathrm{Fe} 3 \mathrm{~d}$ level for spinel-type compound [34]. The absorption intensity of the nanoferrites $\mathrm{ZnFe}_{2} \mathrm{O}_{4}$ was extremely enhanced compared to other samples to be in the order: $\mathrm{ZnFe}_{2} \mathrm{O}_{4}>\mathrm{Co} \mathrm{Fe}_{2} \mathrm{O}_{4}>\mathrm{MnFe}_{2} \mathrm{O}_{4}$. This was due to the good dispersion of $\mathrm{ZnFe}_{2} \mathrm{O}_{4}$ as well as to the decreased crystallites size; that resulted in quantum confinement effects [35], comparatively as derived from TEM observation. The facile formation of $\mathrm{ZnFe}_{2} \mathrm{O}_{4}$ and the exhibited decreased crystallites size could be responsible for increasing the electronic density and thus increasing the absorption intensity.

The values of optical transition obtained by extrapolating the straight line portion to energy axis at zero absorption coefficients give the direct optical band gaps. In particular, we found that $\mathrm{E}_{\mathrm{g}}$ decreases in the following sequence: $\mathrm{Zn}$ $\mathrm{Fe}_{2} \mathrm{O}_{4}(1.3 \mathrm{eV})>\mathrm{MnFe}_{2} \mathrm{O}_{4}(1.25 \mathrm{eV})>\mathrm{CoFe}_{2} \mathrm{O}_{4}$ $(0.9 \mathrm{eV})$. These results indicate the capability of later samples for capturing visible light than corresponding ones synthesized by different methods as well as exceeding $\mathrm{TiO}_{2}$ photocatalytic nanoparticles [36]. Smaller band gap value was clearly observed for the nanoferrite $\mathrm{CoFe}_{2} \mathrm{O}_{4}$. However, this later sample indicates lower absorption intensity than $\mathrm{ZnF}_{2} \mathrm{O}_{4}$. Indeed, this is because Co that is associated with excess electrons; not stable as half-filled (Mn) or completely filled ( $\mathrm{Zn}$ ), can easily excited when coupled with $\mathrm{Fe}$ ions and exposed to photoirradiation, then it can be excited to inject electrons into the conduction band of Fe-O. The evolution of additional sub-band-gap energy levels that are induced by the abundant surface and interface defects in the agglomerated nanoparticles also decreases $\mathrm{E}_{\mathrm{g}}$ value. The inverse relationship of band gap $(1.3 \mathrm{eV})$ with particle size $(6.27 \mathrm{~nm})$ for $\mathrm{ZnFe}_{2} \mathrm{O}_{4}$ (Table 1) was attributed to the defects or due to change in hybridization with the change in cell volume; and this specific sample has shown the highest cell volume. The as-prepared materials displayed excellent absorption in the visible region justifying their optical applications.

\subsection{Catalytic reduction of nitroarenes com- pounds}

The reduction of 4-NP over the nanoferrite 
Islam Ibrahim, et al.

samples in the presence of $\mathrm{NaBH}_{4}$ was previously investigated on similar samples for the useful production of 4-AP [37-38]. However, our synthesized samples showed comparatively fascinating higher performances even under dark conditions. This reaction was used as a model reaction not only to examine surface texturing and the effect of varying parameters while synthesizing ferrite nanoarchitectures but also investigating the effects of structural changes while nanoferrites syntheses on their catalytic performances. It is observed that when $\mathrm{NaBH}_{4}$ solution was added to the 4-NP solution, the colour of the solution was intensified via giving a peak maximum at $\lambda=401 \mathrm{~nm}$, indicative of formation of 4-nitrophenolate ions. This solution was stable for hours in absence of any catalyst emphasizing that no hydrogenation reaction took place and rather confirm that this reaction is preceded catalytically. Interestingly, after the addition of nanoferrites to the solution containing 4-NP + $\mathrm{NaBH}_{4}$; while stirring in the dark, there was a continuous fading of the yellow color until vanishing. This indeed occurs via a decrease in the absorption peak of max. At $\lambda=401 \mathrm{~nm}$ with simultaneous evolution of that $\lambda=300 \mathrm{~nm}$ due to 4-AP formation, Fig 6. This Figure indicates the reduction that occurred on $\mathrm{MnFe}_{2} \mathrm{O}_{4}$ takes place and accomplished in 270 second, the fastest ever reduction reaction accomplished so far under dark condition on similar samples. The UV-Vis spectra show an isosbestic point (Fig. (6), 320 $\mathrm{nm}$ ), illustrating that the catalytic reduction of 4-NP yields only 4-AP without by-products and proceeds via only one consistent mechanism [39]. Plotting $A_{t} / A_{o}$ vs. $t$ (Fig.7) indicates an abrupt decrease in the concentration of 4-nitrophenolate ion in the first $90 \mathrm{sec}$ of the reduction in presence of $\mathrm{MnFe}_{2} \mathrm{O}_{4}$ surpassing that of Co$\mathrm{Fe}_{2} \mathrm{O}_{4}$ probably due to the facile evolution of $\mathrm{H}_{2}$ over the former, comparatively. The inset Figure shows that the nitrophenolate color still exists till 80 min reaction time in case of $\mathrm{ZnFe}_{2} \mathrm{O}_{4}$ giving reduction conversion comprised of $80 \%$. Plotting $\ln \mathrm{A}_{\mathrm{o}} / \mathrm{A}_{\mathrm{t}}$ vs. $\mathrm{t}(\mathrm{sec})$ indicates straight lines (Fig.8) with slopes representing reaction rate constants. These lines indicate that this reduction reaction follows pseudo-first order rate kinetics. The rate constant values performed at $298 \mathrm{~K}$ were in the order: $\mathrm{MnFe}_{2} \mathrm{O}_{4}\left(0.011 \mathrm{sec}^{-1}\right)>\mathrm{CoFe}_{2} \mathrm{O}_{4}(0.0089$ $\left.\mathrm{sec}^{-1}\right)>\mathrm{ZnFe}_{2} \mathrm{O}_{4}\left(0.0271 \mathrm{~min}^{-1}\right)$. The inset Figure represents $\mathrm{ZnFe}_{2} \mathrm{O}_{4}$ nanocatalyst signifying the disappearance of 4-NP color in minute's reaction time not in seconds as depicted for Mn and Co ferrites. Indeed, it is clarified that the catalytic reduction performance of later nanoferrites exceeded that of $\mathrm{ZnFe}_{2} \mathrm{O}_{4}$ and $\mathrm{MnFe}_{2} \mathrm{O}_{4}$ surpassed that of $\mathrm{CoFe}_{2} \mathrm{O}_{4}$ by a factor of 1.24. Based on the experimental results, one can attribute the increase of the reduction rate of $\mathrm{MnFe}_{2} \mathrm{O}_{4}$ was not due to decreased crystallites size and surface area values but to the increased pore radius and pore volume values. Accordingly, based on the committed high catalytic potential of $\mathrm{MnFe}_{2} \mathrm{O}_{4}$, we chosen it to perform some further reactions. The rate constants obtained for the reduction of 4-nitrophenol via our synthesized nanoferrites were markedly higher as compared to those mentioned in literatures where expensive metal composites were used as catalysts $[14,23,38]$. Furthermore, the facile procedure employed in this work in synthesizing magnetically separable nanoferrites is a good approach for alternative catalysts for nitrophenols reduction. To explore the applicability of the $\mathrm{MnFe}_{2} \mathrm{O}_{4}$ catalyst and its reuse, cycles of newly catalyst were tested for the reduction of 4-NP (Fig. 9). Experiments were performed where the nanocatalyst $\mathrm{MnFe}_{2} \mathrm{O}_{4}$ was recovered and reused without any treatment via keeping all other parameters constant. The results revealed that $\mathrm{MnFe}_{2} \mathrm{O}_{4}$ shows a very good activity for five catalytic runs with a small loss in the 4-NP conversion. The conversion of 4-NP after the fifth run maintains activity as high as $75 \%$ concluding that the $\mathrm{MnFe}_{2} \mathrm{O}_{4}$ catalyst possesses reasonable stability and high potentiality for practical applications.

The reduction of 2,4,6-NP and 4-NA was also achieved using the nanocatalyst $\mathrm{MnFe}_{2} \mathrm{O}_{4}$ under similar reaction conditions. 2,4,6-NP shows absorption peak at $355 \mathrm{~nm}$ in the UV-visible spectrum. With the catalyst addition, the yellow color of the reaction mixture started fading and the absorption intensity of the peak at $\lambda=355$ $\mathrm{nm}$ started decreasing illustrating the reduction of 2,4,6-NP to 2,4,6-AP via existence of a new peak at $\lambda=299 \mathrm{~nm}$. The reaction was fast and completed in $270 \mathrm{sec}$ with rate constant equal 
Synthesis of Magnetically Recyclable Spinel Ferrite (MFe2O4, M= Zn, Co,

$0.01134 \mathrm{sec}^{-1}$ (Fig. 10). Similarly, 4-NA absorbs at $\lambda=382 \mathrm{~nm}$ in the UV-Visible spectrum and the progress of the reaction was followed via existence of a new peak at $304 \mathrm{~nm}$ representing the corresponding amino-compound. The percent conversion for the reduction of 4-NA using $\mathrm{MnFe}_{2} \mathrm{O}_{4}$ seen in Fig. 11; and completed in 270 sec, indicated rate constant equal $0.01355 \mathrm{sec}^{-1}$ (in-set Fig.11).

It can be seen that the rates of reduction of the three of nitro-aromatics performed using $\mathrm{Mn}$ $\mathrm{Fe}_{2} \mathrm{O}_{4}$ followed the order; 4-NA $\left(0.01355 \mathrm{sec}^{-1}\right)>$ 2,4,6-NP $\left(0.01134 \mathrm{sec}^{-1}\right)>4-\mathrm{NP}\left(0.01061 \mathrm{sec}^{-1}\right)$. It has been acknowledged from literatures [39] that the reduction reaction proceeds via formation of nitrophenolate ion as an intermediate in NPs or via hydroxylamine in 4-NA. The order of reactivity of nitro-aromatics can be explained on the basis of two factors namely the formation of intermediates and their reactivity's. For the formation of nitrophenolate ion, the acidic strength for example of nitrophenols plays an important role where $\mathrm{NaBH}_{4}$ acts as a Lewis base. The order of acidic strength of the nitroaromatics is 2,4,6-NP $>4-\mathrm{NA}>4-\mathrm{NP}$ and the stability of nitrophenolate ions follow the same order. This is due to the fact that in 2,4,6-nitrophenolate ion, the -ve charge of oxygen is delocalized through the benzene ring that stabilized via resonance besides inductive effect of nitro groups those further contribute to the facile liberation of $\mathrm{H}$ ion. However, exceeding the reduction rate of 4-NA on $\mathrm{MnFe}_{2} \mathrm{O}_{4}$ compared to other nitroaromatics could be due to the electron donating ability of $\mathrm{NH}_{2}$ as well as due to decreasing the electronegativity of nitrogen in aniline moieties compared to oxygen of hydroxyl group in nitrophenol compounds and thus nitrophenolate ions. Also picric acid suffers from steric hindrance upon orientation on the catalyst surface rather than 4-NA. In these nitroaniline molecules, the lone pair of electron of the amino nitrogen atom is attracted towards the strong electron withdrawing $\mathrm{NO}_{2}$ groups resulting in a resonating structure. Hence, the amino nitrogen becomes positively charged in nitroaniline by which an electrostatic interaction with $\mathrm{MnFe}_{2} \mathrm{O}_{4}$ at the $\mathrm{pH}_{\text {zpc }}$ equal 7.10 is expected. It wise reporting that nitroarenes solution acquire alkalinity in the $\mathrm{pH}$ range 9.6-
9.95 while performing the reduction reactions. Accordingly, at later margin $\mathrm{MnFe}_{2} \mathrm{O}_{4}$ acquires negative charges on its surface and thus an expected electrostatic repulsion e.g. between the ionized 4-nitrophenolate ions and the ferrite surfaces can be presumed. Conversely, electrostatic attraction is likely between residual positive charges exposed on nitroaniline and those of negative ones created on ferrites surface during interaction. Indeed, the 4-nitrophenolate molecules have an additional -OH group of activating character, which partly reduces the effect of $\mathrm{NO}_{2}$ group increasing its dispersive interactions with $\mathrm{MnFe}_{2} \mathrm{O}_{4}$ however, the residual positive charges on 4-NP groups are lower than those on 4-NA ones. Accordingly, the enhanced electrostatic interaction between $\mathrm{MnFe}_{2} \mathrm{O}_{4}$ with the residual positive charges created on 4-NA exceeded that with 4-NP facilitated the reduction of the former than that of the later. Increasing the reaction rate of $\mathrm{MnFe}_{2} \mathrm{O}_{4}$ with nitroaniline than with 4-nitrophenol is also due to their hydrophobicity determined by their solubilities: (cs,4-NP $=0.087$ $\mathrm{mol} / \mathrm{l}, \mathrm{cs}, \mathrm{NA}=0.015 \mathrm{~mol} / \mathrm{l})$, and the effect of adsorbate functional groups and their specific interactions with the active sites of nanoferrite surface. However, increasing the reduction rate of nitroarenes on $\mathrm{CoFe}_{2} \mathrm{O}_{4}$ and $\mathrm{MnFe}_{2} \mathrm{O}_{4}$ than on $\mathrm{ZnFe}_{2} \mathrm{O}_{4}$ is presumably due to exceeding the adsorption of nitrocompounds on former ferrites than that on the later facilitated by electrostatic forces.

\section{CONCLUSION}

In conclusion, $\mathrm{MFe}_{2} \mathrm{O}_{4}(\mathrm{M}=\mathrm{Zn}, \mathrm{Co}, \mathrm{Mn})$ nanoparticles $(6-10 \mathrm{~nm})$ were successfully synthesized in a pure spinel form using a PVA template-engaged reaction via a sol gel-hydrothermal technique followed by heating at 573 $\mathrm{k}$ for $6 \mathrm{~h}$ in air. These materials exhibited high catalytic reduction capabilities toward 4-NA and 4-NP and 2,4,6-NP. The merits of the versatile nanostructures and the high magnetic properties make $\mathrm{MnFe}_{2} \mathrm{O}_{4}$ nanoparticles very prospective candidates for aminoaromatics reduction under dark conditions with great performances exceeded those in literatures under similar cnditions. The significant enhancement in reduction activity can be ascribed to the $\mathrm{MnFe}_{2} \mathrm{O}_{4}$ surface that 
Islam Ibrahim, et al.

was favorable as an efficient adsorbent; in the sense of increasing mesoporosity character via enhancing pore volume and pore radius values comparatively, and to the inter-valence electron charge transfer between $\mathrm{Mn}^{2+}-\mathrm{Mn}^{3+}$ and $\mathrm{Fe}^{2+}$ $\mathrm{Fe}^{3+}$ ion pairs..

\section{REFERENCES}

[1] J. R. Chiou, B. H. Lai, K. C. Hsu, D. H. Chen, J Hazard Mater 248-249 (2013) 394-400.

[2] Y. Shaoqing, H. Jun, W. Jianlong, Radiat. Phys.Chem 79 (2010) 1039-1046.

[3] M. Megharaj, H. W. Pearson, K. Venkateswarlu, Arch Environ Contam Toxicol 21(1991) 578-584.

[4] R. Dai, J. Chen, J. Lin, S. Xia, S. Chen, Y. Deng, J. Hazard Mater 170(2009)141-143.

[5] A. C. Apolinario, A. M. T. Silva, B. F. Machado, H. T. Gomes, P. P. Araujo, J. L. Figueredo, Appl Catal B: Environ 84(2008)75-86.

[6] V. Maurino, C. Minero, E. Pelizzetti, P. Piccinini, N. Serpone, H. Hidaka, J. Photochem. Photobiol. A Chem: 109(1997)171-176.

[7] P. Xiong, Y. Fu, L. Wang, X. Wang Chem. Eng. J. 195196(2012)149-157.

[8] F. R. Zaggout, N. A. Ghalwa. J. Environ. Manag. 86(2008)291-296.

[9] X. Zhu, J. Ni, Electrochim Acta 56(2011)10371-10377.

[10] Y. Y. Chu, Y. Qian, W. J. Wang, X. L. Deng, J. Hazard. Mater. 199-200(2012)179-185.

[11] C. Rizhi, D. Yan, X. Weihong, X. Nanping, Chin J Chem. Eng. 15(2007)884-888.

[12] Z. Wu, J. Chen, Q. Di, M. Zhang, Catal. Commun. 18(2012)55-59.

[13] Y. Du, H. Chen, R. Chen, N. Xu, Appl. Catal A Gen: 277(2004)259-264.

[14] K. I. Min, J. S. Choi, Y. M. Chung, W. S. Ahn, R. Ryoo, P. K. Lim, Appl. Catal A Gen: 337(2008)97-104.

[15] H. V. K. Udupa, M. V. Rao, Electrochim Acta 12(1967)353-361.

[16] K. Polat, M. L. Aksu, A. T. Pekel, J Appl. Electrochem. 32(2002)217-223.

[17] F. Taghavi, C. Falamaki, A. Shabanov, L. Bayrami, R. Roumianfar, Appl. Catal A Gen: 407(2011)173-180.

[18] R. Chen, Q. Wang, Y. Du, W. Xing, N. Xu, Chem. Eng. J. 145(2009)371-376.

[19] S. Gazi, R. Ananthakrishnan, Appl. Catal B: Environ. 105(2011)317-325.
[20] M. M. Mohamed, M. S. Al-Sharif, Appl. Catal.B: Environ 142-143(2013)432-441; M. M. Mohamed, M. S. Al-Sharif, Materials Chemistry and Physics 136(2012) 528-537.

[21] M. Kumarraja, K. Pitchumani, Appl. Catal A: Gen 265(2004)135-139.

[22] Y. Kojoma, K. Suzuki, K. Fukumoto, M. Sasaki, T. Yamamoto, Y. Kawai, Int. J. Hydrogen Energy 27(2002)1029-1034.

[23] U. B. Demirci, F. Garin, J. Mol. Catal A: Chem 279(2008)57-62.

[24] R. R. Mandlimath, B. Gopal, J. Mol. Catal A: Chem 350(2011)9-15.

[25] Y. C. Chang, D. H. Chen, J. Hazard. Mater. 165(2009)664-669.

[26] X. Du, J. He, J. Zhu, L. Sun, S. An S, Appl. Surf Sci. 258(2012)2717-2723.

[27] Kalbasi RJ, Nourbakhsh AA, Babaknezhad F. Catal Commun. 12(2011)955-960.

[28] J. Feng, L. Sua, Y. Ma, C. Ren, Q. Guo, X. Chen, Chem. Eng. J. 221(2013)16-24.

[29] S. Singhal, T. Namgyal, J. Singh, K. Chandra, S. Bansal, Ceram. Int. 37(2011)1833-1837.

[30] J. Z. Jiang, P. Wynn, S. Morup, T. Okada, F. J. Berry, Nanostructured Materials, 12(5) (1999) 737-740.

[31] R. Tholkappiyan, K.Vishista, Physica B 448(2014)177-183.

[32] F. Li, H. Wang, L. Wang, J. Wang, J .Magn .Magn. Mat. 309 (2007) 295-299.

[33] R. Kalai Selvan, C.O. Augustin, C. Sanjeeviraja, V.G. Pol, A. Gedanken, Materials Chemistry and Physics 99 (2006) 109-116.

[34] K. He, C.Y. Xu, L. Zhen, W.Z. Shao, Mater. Lett. 61 (2007) 3159.

[35] A. Manikandan, J. Judith Vijaya, M. Sundararajan, C. Meganathan, L. John Kennedy, M. Bououdina, Superlattices and Microstructures 64 (2013) 118-131

[36] M. M. Mohamed, Micro. \& Mesoporous Materials 109, 1-3 (2008) 445.

[37] Q. Cui, B. Xia, St. Mitzscherling, A. Masic, L. Li, M. Bargheer, H. Möhwald, Colloids and Surfaces A: Physicochem. Eng. Aspects 465 (2015) 20-25

[38] A.Goyal, S. Bansal, P. Samuel, V. Kumar, $\underline{\text { S. }}$ Singhal,_J. Mater. Chem. A, 2(2014) 18848-18860.

[39] Z. M. El-Bahy, Applied Catalysis A: General 468 (2013) 175- 